Conclusion: Although this study is unable to show that anti-resorptive treatment should be started in the first year after discontinuation of TPTD, it is promising since the difference between the medians in the total hip BMD values obtained until one year and after one year are marginally significant. These results can be linked to the small sample size and highlight the need for further studies in this area.

REFERENCES

[1] Napoli N, Langdahl BL, Ljunggren Ö, Lespessailles E, Kapetanos G, Kocjan T, Nikolic T, Eiken P, Petto H, Moll T, Lindh E, Marin F. Effects of Teriparatide in Patients with Osteoporosis in Clinical Practice: 42-Month Results During and After Discontinuation of Treatment from the European Extended Forsteo® Observational Study (ExFOS). Calcif Tissue Int. 2018 Oct;103(4):359371. doi: 10.1007/s00223-018-0437-x. Epub 2018 Jun 16. PMID: 29909449; PMCID: PMC6153867.

Disclosure of Interests: None declared.

DOI: 10.1136/annrheumdis-2021-eular.2964

\section{POS1114 INFECTION RISK AMONG RHEUMATIC PATIENTS RECEIVING DENOSUMAB THERAPY: SINGLE CENTRE EXPERIENCE}

K. L. Ng ${ }^{1}$, M. Mohd Zain', I. S. Lau ${ }^{1} .{ }^{1}$ Selayang Hospital, Rheumatology, Batu Caves, Malaysia

Background: Osteoporosis (OS) is common in rheumatic diseasas (RMD). OS fracture leads to morbidity and premature mortality. The treatment for OS is well established with good long term safety profile. Oral bisphosphonate (BIS) is recommended as initial treatment option for both postmenopausal and glucocorticoid induced OS. Denosumab (DSB), is the noninferior alternative option. Despite its efficacy, DSB was linked with elevated infection risk in non RMD. Yet, data in RMD is lacking.

Objectives: To determine the infection risk and associated factors in RMD patients receiving DSB.

Methods: This is retrospective cohort study. Data was extracted from medical database (between Jan 2010 \& Dec 2018) at Selayang Hospital, Malaysia. Descriptive statistical analysis, logistic regression (LR) and cox (proportional hazard) regression [CPHR] were the analysis methods.

Results: 50 cases were analysed. $96 \%$ were female. The median age was 72.5 \pm 12.7 years. The primary rheumatological disorders were rheumatoid arthritis (48\%), OS (24\%) and systemic lupus erythematosus (10\%). $92 \%$ had $\geq 1$ comorbidity including metabolic/cardiovascular diseases (74\%), chronic lung diseases (CLD) (40\%) and diabetes mellitus (DM) (22\%). 54\% had disease modifying anti rheumatic drug (DMARD) therapy; majority (59.2\%) received single conventional synthetic DMARD. Only $7.4 \%$ received combination biologic DMARD therapy. $28 \%$ had received prednisolone therapy, with dose $<7.5 \mathrm{mg}$ OD in $78.6 \%$.

The median age at DSB initiation was $71 \pm 12.4$ years. $38 \%$ had fracture history and $88 \%$ had received previous OS treatment.

In total, 13 infection episodes were recorded. The infection risk was $26 \%$ \& incidence rate was 134 cases per 1000 person-years. $84.6 \%$ required hospitalisation and $38.5 \%$ were severe cases. The mortality rate was $23.1 \%$. The mean DSB treatment duration to first infection was $15.46 \pm 11.9$ months.

Univariate LR showed infection risk and hospitalisation were higher with longer DSB treatment duration, OR $1.062(95 \% \mathrm{Cl}$ : $1.010-1.117), \mathrm{p}=0.018)$ \& OR 1.057 (95\% Cl: $1.003-1.114, p=0.037$ ), respectively. These risks were lower in absence of steroid use, OR $0.2(95 \% \mathrm{Cl}: 0.051-0.784, \mathrm{p}=0.021)$ and OR 0.215 (95\% Cl: $0.052-0.889, p=0.034)$, respectively. Additionally, infection risk was lower in absence of CLD, OR $0.188(95 \% \mathrm{Cl}: 0.048-0.742, \mathrm{p}=0.017)$ and hospitalisation was lower without concomitant DM, OR 0.050 (95\% Cl: 0.050 - 0.950, $p=0.043$ ). Yet, multivariate LR did not infer the above predictions, after adjustment made for age, gender, rheumatological diseases, comorbidity, DMARD therapy and steroid dosing. For severe infection and case fatality, no predictive factors were identified.

CPHR showed patients without steroid use had lower fatality risk, HR 0.077 $(95 \% \mathrm{Cl}: 0.007-0.864, p=0.038)$. With confounding factors (age, gender, previous infection and comorbidity), the observed difference was insignificant.

Conclusion: Risk of infection and hospitalisation could be higher in rheumatic patients receiving longer DSB treatment duration. Concomitant comorbidities (CLD and DM) might increase the risk of infection and/or hospitalisation.

REFERENCES :

[1] Cummings SR, San Martin J, McClung MR, Siris ES, Eastell R, Reid IR, et al. Denosumab for prevention of fractures in postmenopausal women with osteoporosis. N Engl J Med 2009;361:756-65.

[2] Watts NB, Roux C, Modlin JF, Brown JP, Daniels A, Jackson S, Smith S, Zack DJ, Zhou L, Grauer A, Ferrari S. Infections in postmenopausal women with osteoporosis treated with denosumab or placebo: coincidence or causal association? Osteoporos Int. 2012;23(1):327-337.
[3] Prabhakaran S, Pritchard C. Comparison of infection rates in patients receiving denosumab, denosumab and biologics and biologics alone in a suburban rheumatology clinic [abstract]. Arthritis Rheumatol 2014;66 Suppl 10:S409.

[4] Bray V, Bagley A, West S, Etzel C, Kremer J, Kolfenbach J. Infection risk among patients receiving concurrent denosumab and biologic or non-biologic DMARD therapy: An analysis of the Consortium

Acknowledgements: We would like to thank the Director General of Health Malaysia for his permission for this poster presentation.

Disclosure of Interests: None declared.

DOI: 10.1136/annrheumdis-2021-eular.3038

\section{POS1115 \\ DESCRIPTIVE STUDY OF THE PERCEPTIONS AND PREVENTIVE PRACTICES OF POSTMENOPAUSAL TUNISIAN WOMEN REGARDING OSTEOPOROSIS}

S. Ben Jemaa ${ }^{1}$, Y. Mejdoub ${ }^{2}$, H. Fourati3, J. Damak ${ }^{2}$, S. Baklouti3. ${ }^{1}$ Hedi Chaker Hospital, Rheumatology, SFAX, Tunisia; ${ }^{2}$ Hedi Chaker Hospital, Community Medecine, SFAX, Tunisia; ${ }^{1}$ Hedi Chaker Hospital, Rheumatology, SFAX, Tunisia

Background: Due to their serious consequences affecting quality of life, prevention of osteoporosis is considered a priority. Thus, identifying the level of knowledge is useful in developing effective interventions and in guiding public health programs to prevent osteoporosis.

Objectives: The aim of this study is to describe beliefs and practices of menopaused Tunisian women related to health and osteoporosis in order to develop effective and targeted interventions for the prevention of this disease.

Methods: A descriptive cross-sectional study was conducted among menopaused Tunisian women who consult the basic health center in the area of Sfax region in Tunisia. Data collection include socio-demographic characteristics, the "osteoporosis health belief scale" developed by Kim and his colleagues and the daily calcium intake which was calculated by a questionnaire developed by Patrice Fardellone.

Results: We have included 170 women. The mean age was $58.92 \pm 9.07$ years Seventy-seven percent of women were housewives, $14.7 \%$ were active and $8.3 \%$ were retired. Seventy-five percent were married. Forty-two women (24.7\%) were illiterate, sixty-three (37.1\%) were at primary level and $33.5 \%$ were at secondary level. One hundred twelve women $(65.3 \%)$ live in an urban environment, against $34.7 \%$ who belong to a rural environment.

The level of perception of osteoporosis was very altered in $22.9 \%$, altered in $32.4 \%$ and moderately altered in $31.8 \%$ of women. Women's perceptions of the benefits of physical exercise and calcium intake were moderately altered in $42.4 \%$ and $51.2 \%$, respectively. For obstacles to the practice of physical exercise the level of perception was altered in $43.5 \%$ of women. Regarding the obstacles to calcium intake, the perceptions of our population were altered in $32.9 \%$ of cases.

The daily intakes of calcium vary from 215 to $1444 \mathrm{mg}$ per day with an average of $620.20 \pm 204.523 \mathrm{mg} /$ day. Only eight women (4.7\%) had sufficient daily intake. Conclusion: Our study showed that all subscale of the "osteoporosis health belief scale" were altered. Promotion programs should aim at creating a supportive physical and social environment for the adoption of safer behaviors and especially education must be targeted.

\section{REFERENCES:}

[1] Belgacem, A. Nouira, et S. Soussi, « Les perceptions des femmes tunisiennes selon le modèle des croyances liées à la santé et leurs pratiques relativement à l'ostéoporose », Pan Afr Med J, vol. 23, 2016.

[2] H. Ahmadieh, A. Basho, A. Chehade, A. Al Mallah, et A. Dakour, « Perception of peri-menopausal and postmenopausal Lebanese women on osteoporosis: A cross-sectional study », Journal of Clinical \& Translational Endocrinology, vol. 14, p. 19-24, déc. 2018

Disclosure of Interests: None declared.

DOI: 10.1136/annrheumdis-2021-eular.3571

\section{POS1116 ENHANCING OSTEOPOROSIS MANAGEMENT: THE CONTRIBUTION OF FRAX® AND VFA IN TUNISIAN WOMEN}

C. Daldoul ${ }^{1}$, N. El Amri ${ }^{1}$, S. Laataoui ${ }^{1}$, K. Baccouche ${ }^{1}$, H. Zegaloui ${ }^{1}$,

E. Bouajina ${ }^{1} .{ }^{1}$ Farhat Hached Hospital, Rheumatology, Sousse, Tunisia

Background: The FRAX® is a tool proposed by the World Health Organization (WHO) to calculate 10-year fracture risk of hip fracture and major osteoporotic fractures. The utility of this tool is to help treatment decision when it is litigious Previous low trauma fracture represent a factor in FRAX® calculation. However asymptomatic osteoporotic vertebral fractures (VF) identified on X-rays or Vertebral Fracture Assessment (VFA) scans are rarely included. To the best of ou knowledge, there was no previous evaluation of fracture risk in Tunisian women. 